International Scientific Journal Theoretical \& Applied Science

p-ISSN: 2308-4944 (print) $\quad$ e-ISSN: 2409-0085 (online)

Year: $2015 \quad$ Issue: $07 \quad$ Volume: 27

Published: $30.07 .2015 \quad$ http://T-Science.org
Sergey Iosifovich Tatarinov

candidate of historical Sciences, associate Professor, Educational and Scientific Professional Pedagogical Institute of Ukrainian Engineering and Pedagogical

Academy, Ukraine brodiaga-art@ukr.net

SECTION 13. Geography. History. Oceanology. Meteorology.

\title{
THE DIRECTIONS OF THE ACTIVITY DUMA OF DONBASS ON EXAMPLE BAKHMUT'S 1866-1916
}

\begin{abstract}
The legal basis of creation and activities of the Bakhmut City Council are examined. Bakhmut was the center of the county's largest Ekaterinoslav province, occupied half of the current Donetsk region: the election of deputies of the Duma vowels, terms of office, the requirements for candidates for the post of Head and vowels, the order of the election. The function of the representative body, the Duma and the regulatory authority, justices are analyzed. The tax base of the population, commerce and industry, the role of fair trade, ways of filling the local budget expenditure at different times, supervise the implementation of the budget are studied.

Key words: mayor, Duma, the council, the vowels, the budget.

Language: Russian

Citation: Tatarinov SI (2015) THE DIRECTIONS OF THE ACTIVITY DUMA OF DONBASS ON EXAMPLE BAKHMUT'S 1866-1916. ISJ Theoretical \& Applied Science 07 (27): 169-176.

Soi: http://s-o-i.org/1.1/TAS-07-27-30 Doi: crossef http://dx.doi.org/10.15863/TAS.2015.07.27.30

НАПРАВЛЕНИЯ ДЕЯТЕЛЬНОСТИ ДУМ ДОНБАССА НА ПРИМЕРЕ БАХМУТА 1866-1916 ГГ.

Аннотация: Исследованы правовые основы создания и деятельности городской Думы Бахмутацентра крупнейшего уезда Екатеринославской губернии, занимавшего половину нынешней Донецкой области: избрание депутатов-гласных Думы, сроки полномочий, требования к кандидатам на должности Головы и гласных, порядок проведения выборов. Проанализированы функции представительного органаДумы и распорядительного органа-Управы. Изучена база налогообложения населения, торговли и промышленности, роль ярмарочной торговли, пути наполнения местного бюджета, статьи расходов в разные периоды, контроль за исполнением бюджета.

Ключевые слова: городской Голова, Дума, управа, гласные, бюджет.
\end{abstract}

Актуальность темы. В независимой Украине свыше 20 лет длятся эксперименты с местным самоуправлением, каждая новая власть или партия делают попытки расширить полномочия городских Советов, но это приводило к бюрократизации и усилению централизации, ограничения прав громад.

Изучение вопросов местного самоуправления стало актуальным в современной Украине в связи с Конституционной реформой, предусматривающей новое административнотерриториальное деление на регионы, уезды и волости. При этом планируется максимальная децентрализация финансов, создание самодостаточных органов местног самоуправления.
Поэтому опыт 50-летней деятельности Дум до 1917 г. применим к сегодняшней реформе в Украине.

Историография вопроса. После Крестьянской реформы 1861 г. и учреждения системы городского самоуправления с 1870 г. в Российской империи, правительство постоянно регулировал функции городских Дум [16].

Представители передовых слоев русского общества, ученые-правоведы прилагали усилия для расширения демократических принципов самоуправления, проводили исследования проблем местных земских органов $[1 ; 2 ; 9 ; 17 ; 18$; 48].

При советской власти была скопирована предыдущая модель выборных представителей в городах, но она носила декоративный характер [13]. 
В последнее время исследования в Украине истории местного самоуправления носили обобщающий характер [3, с.311-318; 5; 6, с.53-67; 50, c.7-12].

Автор статьи и другие исследователи впервые начали изучать историю городского самоуправления в Донецкой области на примере Бахмута-Артемовска в 90-е годы ХХ столетия [41-47].

Основной текст. Бахмут как город существовал с 1701 г. Бахмутский уезд (17871920) был одной из наибольших административных единиц Российской империи (второй после Московского) в составе Екатеринославской губернии : 8.106 квадратных верст, разделялся на 22-24 волости, насчитывалась 281 сельская община, 1 город центр уезда Бахмут, 931 разных поселений.

Юзовка по промышленному потенциалу, численностью населения превосходила центр уезда.

Поселки Горловка, Енакиево, Гришино давали значительные доходы земского бюджета, но до июля в 1917 г. эти поселки управлялись заводской администрацией, что сдерживало социально-экономическое развитие уезда.

Население уезда росло быстрыми темпами: в 90-ые годы ХІХ века проживало 200.177 тыс. лиц, в 1915 г. численность населения достигла отметки 560.400 тыс. лиц.

Плотность населения составляла 69 лиц на одну квадратную версту.

В Бахмутському уезде земское самоуправление (местное самоуправление) было введено с 5 апреля 1866 г.

Бахмутская городская Дума владела землею как источником пополнения казны города. С 2 ноября 1862 г. правительством России были утверждены правила выделения земель, которые принадлежат городам Новороссийского края под частные сады и виноградники. С разрешения губернского начальства городская Дума получила возможность отвести не более $1 / 10$ части городских земель под садово-виноградарские участки для горожан. В одни руки выделялось не более десятины. Владелец участка в течение трех лет должен был ее освоить: оградить или обкопать рвом, посадить не менее 100 фруктовых деревьев или 1200 кустов винограда. Со дня отведения он освобождался от всякого налога[4]. Каждые 3 года Бахмутская Дума проводила осмотр участков и, в случае выполнения условий освоения, владелец получал документ на право постоянного пользования землей, а сам участок облагался ежегодным сбором в пользу города в размере 30 копеек серебром. Если арендаторы смогли воспользоваться предоставленной возможностью, то через несколько лет большая часть урожая, естественно, начала поступать на рынок.

Город владел и отдавал в аренду 3,7 тыс. десятин земле под водяные мельницы, заводы кирпичные, салотопельные, стеклянные, костопальные, кузницы, бойни, керосиновые склады, земледелие, огороды, сенокошение и выпасы. Все было учтено [11].

В 1866 г. в Бахмуте: жителей 10103, домов каменных 172, деревянных 1700. На Торговой площади 48 каменных магазинов-лавок, 36 временных. Купцов 3-й гильдии 140, из других городов 17. Мещан было 4179 лиц. В городе действовали 5 кирпичных, 2 мыловаренных, 7 салотопельних, 5 свечных, 2 известняковых и костопальный заводы, 2 парикмахерских. Действовали 5 православных церквей и католический храм, 2 синагоги, социальносословный состав: дворян потомственных 68, лиц духовных 69, почетных граждан 4, купцов 517, офицеров и солдат 386, отставных чинов 133 , крестьян 3392, мещан 4493, иностранных подданных 28 [19].

В 1872 году в Бахмуте было: 17990 жителей, каменных домов 128, деревянных 1661, каменных магазинов 53, деревянных 77. Водкой, вином торговали 183 лица. Действовали 5 салотопельных, 4 свечных, винокуренный, табачный, пивоваренный заводы, 2 мельницы. Стоимость всего имущества города представляла 774,7 тыс. рублей. Город имел почтовую станцию Павлоградско-Славяносербского тракта, телеграф. Существовали Тюремный замок и Камера мирового суда [20].

В 80-ые годы XIX века Бахмут имел: домов каменных 172, деревянных 1458 на сумму 634 тыс. рублей, магазинов каменных 44, деревянных 109 на сумму 100 тыс. рублей. Насчитывалось 569 ремесленников-кустарей, 744 купца при населении города 12109 человек. Общий объем прибыли местной промышленности составлял 130 тыс. рублей, ярмарки и розничная торговля давали 235 тыс. рублей [21].

Городскую реформу регулировало «Городовое положение» от 28 июня 1870 года. Положение ввело прусскую систему, в соответствии с которой депутатов - гласных избирали налогоплательщики, которые платили определённую сумму налогов (денежный, материальный ценз). Списки налогоплательщиков составляли из тех, кто платил наибольшие налоги, кончая мелкими плательщиками. Городское положение обеспечивало достаточно консервативный состав городских Дум. В выборах участвовали лица, которые достигли 25 лет, владельцы недвижимости, промышленных предприятий, лица, которые занимались кустарными промыслами или мелкой торговлей из любого 
сословия. Не допускались к участию в выборах лица с судимостью, отстраненные от должностей, подследственные, лишенные духовного звания. Должностные лица судов и полиции, женщины принимали участие в выборах через представителей. Голосование было тайным. Дума и управа избирались на 4 года, половина состава обновлялась каждые 2 года. Городской Голова мог отменить решение управы. Устанавливалось предельное число лиц не христианского вероисповедания, которое допускалось в состав Думы - одна треть. Городской Голова не мог быть еврейской национальности [14, 42]. Контрольные функции имели начальники губерний. В статье 76 Городского положения определялся механизм губернаторского контроля: постановления городских Дум в обязательном порядке подавались на рассмотрение губернатора, он имел право в двухнедельный срок остановить их действие за несоответствие закону. Обжаловали эти решения городские Думы в губернских по городским делам Присутствиях, которые состояли из губернатора, вице-губернатора, председателя губернской земской управы, Головы губернского города, председателя губернского Съезда мировых судей. Решения Присутствия действовали безотлагательно. Дума могла обжаловать их в Правительственный Сенат, решения которого были окончательными. Ожидать постановления приходилось очень долго $[14,42]$. Губернатор утверждал городских Голов уездных и заштатных городов, подавал характеристики министру внутренних дел. Министр МВД сообщал губернатору о позитивном или негативном решении. В МВД посылали дела всех кандидатов, которые набрали больше голосов «за». Нередко министр избирал кандидата по своему усмотрению, не обращал внимания на то, кто действительно набрал больше голосов [14, 42].

В Бахмуте гласным мог стать житель, который имел недвижимость на 3 тысячи рублей серебром. Первым Головою Бахмута стал купец Василий Ангельевич Ангелиди из Таганрога, секретарем Думы Иван Степанович Педанов. В 1866 - 1867 гг. в городскую Думу было избрано 7 гласных, среди них иудеи Янкель Липарев, Гершель Тисменицкий [12]. В.А. Ангелиди позаботился об открытии Высшего народного училища, первой мужской гимназии, поощрил немцев Фарке и Мартенса начать строительство водопровода. Короткое время Головой Бахмута был И.С. Педанов.

Ярким примером конфликтов имущественных интересов деятелей Бахмутской Думы стала история с выходом книги С. Крамарева «ЛУЧШЕ СЛУШАТЬ УПРАВУ, А НЕ МНИМЫХ БЛАГОДЕТЕЛЕЙ». Крамарев писал - «...что творится в Бахмутской Думе под руководством одного лица, которое установило порядок вопреки 64 ст. Городского положения решать такие вопросы, которые не совпадают с его взглядами, путем закрытого баллотированияголосования (не спрашивая Думу, каким способом она желает решать вопрос) и этим способом отвергать самые полезные заявления и предложения» [15]. Протест вызывали решения по вопросам командировки по предложению Педанова гласного Шабашева в Петербург из-за невыполнения обязательств Донецкой железной дорогой по строительству мостов и шоссе. Поездка должна была быть за их счет, но Голова И.М. Клейменов изменил решение в Журнале заседаний Думы (фактически подделал его) о выдаче Шабашеву 100 руб. Из 45 гласных Председателя подписями поддержали 22, но при расследовании еще 1 отказался от подписи. Крамарев обвинил Голову Клейменова в нежелании открывать полную мужскую гимназию [15]. Скандал стоил должности Головы И.М. Клейменову.

В 1874 г. городские Думы получили право определять количество мест продажи, запрещать торговлю спиртными напитками в тех или других местностях. По реформе 1885 г. вносились коррективы к «Положение о трактирных заведениях» - сборы с чайных и других заведений без продажи горячительных напитков, пивных с продажей горячей еды в пользу города не должны были превышать сумму, уплаченную ими к казначейству $[8,22,23]$. Правилами 14 мая в 1885 г. городским Думам предоставлялись полномочия на разрешение открытия заведений розничной торговли спиртными напитками [32, 33].

С 1884 г. гласным Думы, членом Управы и заместителем Головы был избран В.И. Першин, ставший Головой в 1887 г.

Бюджет Бахмута составлял в 1881 г.: прибыли 37340 руб. (+10 тыс. к плану), расходы 36069 руб. Выдано торговых патентов 2388 (прирост 414) из-за роста сети железных дорог через Бахмут. Бюджет города в 1882 г. составлял: прибыли - 36,4 тыс. руб., расходы - 33,8 тыс. руб. В 1894 г. прибыли Бахмута составили 53638 руб. $[24,26]$.

Большое значение имел для наполнения бюджета рост числа оптовых ярмарок. В 1881 г. в Екатеринославской губернии состоялись 480 ярмарки. В 1882 г. на Рождественской ярмарке в Бахмуте продано товаров 300 тис. руб. и она стала одной из 3 наибольших (Ростов, Екатеринослав) в губернии. В 1884 г. ПетроПавловська ярмарка Бахмута сравнялась с Екатеринославом за объемами товаров $[24,26]$.

Бахмут в 1881 г. имел мыловаренный, 2 сальных свечей, 3 салотопных, канатный, пивоваренный, 5 известняковых завода, 2 
газированных вод, 4 кирпичных, солеваренный, стеклянный заводы - всего 21. В уезде работали сахарный завод, 33 угольных рудника, литейный. 41 предприятие [24].

48 граждан Бахмута в 1881 году ходатайствовали перед Думой об установлении сбора с товаров, которые провозятся городом, с целью привлечения дополнительных средств для благоустройства и ежегодных ярмарок [7, 34].

Бахмут в 1887 г. занимал 4 место в губернии по количеству предприятий- 18, обьем производства составлял 319,6 тыс. руб., работало 528 лиц [25].

Уезд занимал 1 место в Екатеринославской губернии- имел 52 предприятия, объем производства представлял 9,8 млн. руб. Рабочих было 13432 [25].

Бахмутское казначейство зафиксировало торговый оборот 47,5 тыс. руб. Бахмут провел в 1887 г. 4 ярмарки-привоз товаров на 890 тыс. руб., продажа 324 тыс. руб. «Оптовые продажи почти не ведутся, потому что развивается торговля лавошная». От сильной эпидемии чумы рогатого скота некоторые ярмарки были закрыты [25].

Бахмут в 1887 г. имел 43 тыс. руб. прибыли, расходы составляли 42,6 тыс. руб. Расходы складывались из содержания Думы 8029 руб., возвращение займов 4380 руб., на народное образование 11295 руб., военные расходы 1899 руб., содержание полиции 4147 руб., содержание пожарных 4451 руб., содержание тюрьмы 1020 руб. [25].

Городское Положение 1892 г., автором которого был министр МВД И.М. Дурново, не имело нормы, что городское самоуправление в пределах своей компетенции действует самостоятельно, статьи закона были направлены на ограничение самостоятельности городского самоуправления, полное подчинение их губернии. Положение имело перечень обязательных постановлений (ст.108): о действиях лиц, которые служат при приёме и отправлении товаров; о торговле спиртными напитками; о режиме рабочего дня в торговых и промышленных заведениях в выходные и праздничные дни; о безопасности движения на улицах; о мероприятиях обеспечения общественного порядка в публичных местах. Усиливалось влияние губернаторов на органы городского самоуправления - городской Голова, члены Управ утверждались губернатором. Обязательно утверждались губернатором годовые городские сметы. Документы подавались Думой и управой на рассмотрение МВД через губернатора. При обсуждении дел, которые касались действий городского самоуправления, в состав Присутствия входил выборный от Думы губернского города из ее гласных (ст.12). Губернское по земским и городским делам Присутствие имело право отдавать под суд лиц, избранных в городское самоуправление. Губернатор привлекал Председателей Дум и членов управы к дисциплинарной ответственности. Городским Голова, членам управ предоставлялись чины гражданского Табеля о рангах [13].

В 1895 г. выдано торговых гильдейских патентов в Бахмуте и уезде $2186(+307)$ - 1 место в губернии. Это было связано с «наплывом евреев, выселенных из сельских местностей». Промышленных патентов выдано в Бахмуте в 1895 г. -3192 [35].

Городская Дума выделяла деньги на выплату пособий и пенсий служащимпенсионерам и их вдовам: в 1895 году пенсия была назначена вдове бывшего городского Головы титулярного советника И.С. Педанова в сумме 57 рублей в год. Врачу-пенсионеру О. А. Шкляревскому "за прослуженные им 25 течение в Бахмуте" была назначенная пенсия в размере 252 руб. в год. Ежегодно отпускалось до 10 вагонов угля для бедного городского населения [35].

Дума вела учет всего, что привозилось и продавалось в городе - этим занимались 3-4 члена Управы. В городе проводилось ежегодно по четыре ярмарки, по семь дней каждая, с оборотом 0,6 - 1 млн. руб. Был предел цен на мясо и хлеб в апреле-сентябре, что утверждалось Думой ежегодно.

Статьи Бахмутского бюджета за 2 года.

Таблица 1

\begin{tabular}{|l|c|c|}
\hline Год & 1896 г. [36-37] & 1899 г. [38] \\
\hline Общие доходы & 155,6 тыс. pуб. & 170 тыс. pyб. \\
\hline Расходы & 61,3 тыс. pyб. & 63,6 тыс. pyб. \\
\hline
\end{tabular}

В 1899 г. доходы Бахмута: налог на недвижимость 13809 руб. (17\%), сбор с промыслов 2912 руб., сбор с конных извозчиков 1128 руб., земельный налог 14464 руб. (18\%), аренда городских зданий 1499 руб., другие налоги 45400 руб. (57\%). Всего поступило 79208 руб. [38].

Расходы составили $73 \quad 812$ руб.: на содержание Думы 9308 руб., оплату квартир военным 2557 рублей, содержание полиции 6605 
руб. (9\%), на пожарную команду 6091 руб. (8\%), содержание мостов, бульваров, парков, ремонт зданий, мощение улиц, освещение 11400 руб. (14\%), народное образование 16606 руб. (23\%), медицинская помощь и ветеринария 2900 руб. (4\%) [27].

Общая прибыль городских фабрик и заводов составляла 785000 руб. Общий торговый оборот Бахмута равнялся 2,9 млн. руб., мануфактурные и бакалейные товары продавались на 1,6 млн. руб. В 1899 году было 120 крупных магазинов и 143 лавки, 122 ремесленников производили товаров и услуг на 250000 руб. Только на мощение улиц в 1898 - 1899 годах было потрачено 17627 руб. [27].

Интересным является анализ
распорядительной деятельности Думы и управы. В 1896 г. состоялось 6 общих заседаний Думы, где было рассмотрено 87 вопросов. Голова, гласные Н. Горяинов и Н. Гаврилов собирались на 61 управы (практически ежевоскресно). Рассмотрели 328 вопросов: разрешение на сооружение Есель Добрейцер будки для продажи газовых и фруктовых вод в сквере около Соборной церкви, предложение купца И.М. Клейменова об открытии Отделения Госбанка, "о неудовлетворительном строительстве водопровода, случаях недостатка воды", которые повторяются, о подряде Якову Моисееву на строительство Ремесленного училища, "о разрешении открыть трактир с продажей пивамеда, портера и вина русского". Приблизительно $50 \%$ составляли вопросы коммерции, развития сети магазинчиков, здравоохранение, благоустройство города, народное образование. Ни слова о вмешательстве в дела местной промышленности (только аренда десятин, налоги с производства) [36].

В 1899 г. в Бахмуте было 26 гласных (24 христианина, 2 иудея). Дума собралась на 6 сессий, где рассмотрены 83 вопроса, на 52 заседаниях управы рассмотрено 359 вопросов: о строительстве в Бахмуте Торговых рядов, бойни, здания волостного Правления, нового здания мужской гимназии, Воскресной школы, склада угля для бедных, почтово-телеграфной конторы и Казначейства, о расквартировывании 8-й кавалерийской бригады, о запрете виноторговли накануне праздников и в выходные дни и создание Комитета народной трезвости и другие [38].

Оклады Председателя и гласных-членов управы составляли - соответственно 150 и 60 руб. в месяц, городской архитектор получал 600 руб. на год (50 руб. в месяц), бухгалтер - 300 рублей в год (25 рублей в месяц), брандмейстер - 450 рублей в год (37,6 рублей в месяц), заведующий мужским Владимирским училищем - 300 руб. в год (25 в месяц), старший чин полиции - 180 руб. в год (15 в месяц). Штат Управы состоял из одного общего секретаря (по-видимому, управляющего делами) с окладом 100 руб., одного бухгалтера - 25 руб., 6 канцеляристов с окладами в 30-35 руб. и двух писарей по 20 руб., сторожа и курьера [36-38].

Канцелярия Думы утопала у разного рода бумагах: в 1899 г. их поступило из Петербурга и Екатеринослава 6451, а в ответ переписка составила 3597 единиц. Всего на содержание "аппарата" шло 5-7\% городского бюджета. Расходы Думы "на себя" - сейф за 200 руб., по пуду угля на печь (пуд - 10 копеек), освещение "думских заседаний и заседаний комиссий" требовало керосин на 36 руб. Работали и заседали много [38].

Источниками формирования бюджета города были налоги: на недвижимость 14,3 тыс. руб., торговые сборы (с винных, спиртных магазинов, с трактиров и извоза), с ремесел - 8,1 тис. руб., пошлины разные - 4,2 тис. руб., доходы с городского имущества (с аренды мельниц, за землю под заводами и магазинами) 34 тыс. руб., возвращение городу средств правительством 2,1 тыс. руб. в 1899 г. [27].

Основной налог на недвижимость складывался исходя из ежегодно издаваемых Думой "Книг оценки недвижимого имущества", где по улицам указывались все строения, их владельцы, стоимость в рублях, на основании законодательства раскрывался механизм начисления и уплаты указанного выше налога [27]. Уплату этого налога контролировали гласные В.В. Липчай и Н. С. Смиреномудренский.

Торговыми налогами облагались деревянные и кирпичные, рыбные, мясные, квасные, сенные, гончарные, хлебные, бараночные магазинылавки. Магазины, торговавшие мануфактурой и промтоварами, налогов не платили. Налоги за минеральное сырье платили кирпичные и известковые заводы, солеварный завод Скараманги [27, 36-38].

С многочисленного еврейского населения (евреи составляли 25\% из 21 тыс. жителей) брались налоги - "свечной" и "коробочный". В 1896 г. они составили больше 4850 руб. [36].

Городская Дума обратилась в 1903 году в Хозяйственный департамент МВД с просьбой об установлении сбора от $1 / 8$ до $1 / 2$ копейки с пуда доставленных в Бахмут товаров по железной дороге. Государственный Совет и царь Николай II позволили собирать по $1 / 2$ копейки с пуда товаров, что дало 83,2 тысяч рублей для мощения улиц Николаевской, Большой и Малой Харьковской, Соборной на всем их протяжении [34]. Мощение тротуаров, мостовой брусчаткой было отдано купцу Абраму Дулину, камень поставлял зайцевский крестьянин Илья Симко. 
Городской бюджет Бахмута в 1912 году состоял по доходам 157974 руб. и расходам 157899 руб. Недоимка по разным платежам составляла 36568 руб., то есть больше $20 \%$ годового бюджета. Запасной капитал Бахмута составлял свыше 35000 руб. [40].

Правительство постоянно пересматривало и усложняло процедуру избрания гласных городских Дум [14, 48]. Примером этого является Распоряжение Екатеринославского губернатора о собраниях избирателей г. Бахмута во 2-ю Государственную Думу 19 марта 1906 года. Это был «стандарт» имущественного ценза. К выборам допускались лица, которые имели в собственности или наследстве 150 дес. земли, владельцы до 100 дес. арендной горно-заводской земли, владельцы недвижимости в 15 тыс. руб., доверенные лица от женщин и духовенства на собраниях в Бахмуте и Горловке 28 февраля 1906 г. Избиратель должен был предъявить Председателю собрания документ, удостоверяющий личность. Голосование происходило в большом зале уездного земства. Избиратель должен был получить у Председателя бюллетень, куда заносил 3 фамилии губернских выборщиков. Бюллетень выборщик мог получить в течение 3 дней с 16 по 18 марта. В день выборов бюллетени не выдавали. Избиратели с 9 до 20 часов подходили к Председателю, отдавали ему свое удостоверение и вбрасывали бюллетени в ящик. Подсчет голосов происходил на второй день 20 марта в присутствии любых избирателей.

В 1910-1914 гг. право голоса на выборах в городскую Думу по имущественному цензу имели 381 лица - они избирали 35 гласных Думы. В Думе были гласными 2 представителя от земской Управы и представитель духовенства (в Бахмуте было до 150 лиц этого звания).

Анализ состава городской Думы за 1901 1913 гг. показывает, что повторно избирались 50\%. Если в 1901 -1905 гг. в Думе было 29 членов и 6 кандидатов, то в 1913 году соответственно 35 и 8 [30].

В Комитете по квартирному налогу среди 7 членов был иудей Абрам Французов, в Комитете по налогу с недвижимых имуществ -Вениамин Французов [39].
В 1910 году в Екатеринославе состоялась Южно-русская областная выставка, на которую Бахмутская городская Дума представила альбом с иллюстрациями о своей деятельности и была награждена Малой серебряной медалью за благоустройство города [49].

В 1913 году в Бахмуте проживали: русских 21 тыс., поляков - 113, немцев - 76, татар - 89, евреев - 6,4 тыс., иностранных подданных - 104. Можно заметить, что тогдашняя статистика такого населения, как «украинцы» - не знала, не «замечала» [27].

В период I Мировой войны городской Думе насчитывались 36 гласных, Городским Головою стал Н. И. Новгородцев (врач, брат профессора правоведения Петербуржского университета, депутата 1-й Государственной Думы, заместителя председателя партии конституционных демократов П. И. Новгородцева), заместителями были купец Н. А. Апаренко, владелец кирпичного завода А. П. Бадодин, гласными Думы были не только владельцы заводов Венгеровский, Вараксин, Лобасов, Минаев, Новиков, Токарев, В.Г. Французов, но и преподаватель музыки и церковный регент Г.А. Макогон, владелец Парка A. А. Чепурковский, оценщики недвижимых имуществ Н. С. Смиреномудренский, В.В. Липчай [39].

Делами мещан ведала Мещанская управа во главе со старостой Ефимом Колисниченко, членами М. И. Шумным, Шлемой Шепетовским [39].

Выводы и перспективы дальнейших исследований. Создание и деятельность Бахмутской городской Думы базировались на правовой и фискальной базе, которая регулировалась правительством. От оперативности, таланта, глубоких экономических знаний (окончил Одесское коммерческое училище), опыта городского Головы В.И.Першина зависело наполнение бюджета, умелое расходование доходов. Это привело к тому, что Бахмут был одним из заметных городов Екатеринославской губернии. Опыт думского самоуправления по использованию делегированных функций может быть примером для работы местных Советов Украины сегодня.

\section{References:}

1. Achadov A (1907) Gosudarstveinaya vlast' i mestnoe gorodskoe i zemskoe samoupravlenie. - Moscow: Tip. F.Ya. Bugre.

2. Bezobrazov VP (1874) Zemskie uchrezhdeniya i samoupravlenie. - Moscow, 1874.
3. Belokon' MV (2002) Vzaimodeystvie mestnykh organov gosudarstvennogo upravleniya i mestnogo samoupravleniya: istoricheskiy opyt i problemy sovremennosti. Vestnik Zaporozhskogo yuridicheskogo instituta. - № 1, $-2002$. 
4. (1911) Velikaya reforma. - Moscow. - t.3.

5. Gorbachev VP (1995) Gorodskoe samoupravlenie v Ukraine (po reforme 1870 goda). Dis. kand. yurid. nauk. - Khar'kov. Nats. un-t vnutr. del, - 1995. - I80 p.

6. Gritsak I (1996) Mestnoe samoupravlenie Ukrainy $\mathrm{v}$ istorii i sovremennosti. Vestnik Ukrainskoy akademii gosudarstvennogo upravleniya pri Prezidente Ukrainy. - 1996. №1.

7. Dadashov OS, Tatarinov SI, Tutova NA (2010) Ocherki etnicheskoy istorii Donbassa. Artemovsk, 2010, - 108 p.

8. Goncharuk VY (2001) Pravovoe regulirovanie proizvodstva i oborota spirtnykh napitkov $\mathrm{v}$ Russiyskoy imperii vo vtoroy polovine XIX - v nachale XX st. (na materialakh ukrains'kikh guberniy). Dis. kand. yurid. nauk. Khar'kov. KhNU vnutr. del. - 2001. - 195 p.

9. Eropkin A (1905) Zemstvo i narod: k voprosu o narodnom nredstavitel'stve/ A.N.Eropkin//. Moscow. - 1905.

10. (1915) Ekaterinoslavskiy adres-kalendar' na 1915. - Ekaterinoslav.

11. (1867) Zhurnaly Bakhmutskogo uezdnogo zemskogo sobraniya 2 sozyva. - Ekaterinoslav: Tip.Chausskogo. -1867.

12. (1867) Zhurnal Bakhmutskogo uezdnogo zemskogo sobraniya. - Bakhmut. - 1867. - 119 p.

13. Zakharova LG (1968) Zemskaya kontrreforma 1890. - Moscow: Izd-vo MGU, 1968. - 178 p.

14. Kornilov AA (1906) Iz istorii voprosa ob izbirateya'nom pravoe $\mathrm{v}$ zemstve. Proiskhozhdenie zemskoy izbiratel'noy sistsmy 1864 g. i ee dal'neyshie izmeneniya. - SPb. 1906.

15. Kramarev SM (1882) Zapiska po povodu vyrazheniya Bakhmutskogo gorodskogo Golovy 12 maya 1882 goda «luchshe slushat' Upravu, a ne mnimykh blagodeteley». Odessa:tip. Nitche. -1882 .

16. Materialy, sobrannye dlya vysochayshe uchrezhlennoy komissii o preobrazovanii gubernskikh i uezdnykh uchrezhdeniy. - V 4 ch. - SIIb.: Tip. MVD, -1870-1871.

17. Mullov $P$ (1864) Istoricheskoe obozrenie pravitel'stvsnnykh mer po ustroystvu gorodskogo obshchestvennogo upravlennya. SPb. -1864 .

18. Mordovtsev DL (1877) Desyatiletie russkogo zemstva. $1864-1875$. - SPb: Tip. A.A. Kraevskogo, -1877 .

19. (1865) Novorossiyskiy kalendar' na 1866 g. Odessa, - 1865.

20. (1872) Novorossiyskiy kalendar' na 1872 g. Odessa, -1872 .

21. (1879) Novorossiyskiy kalendar' na 1880 g. Odessa, -1879 .
22. (1885) Novme uzakonivaniya o piteynoy torgovle//Vestiik fnnansov, promyshlsnnosti i torgovli. - 1885. - №32. Ob uchrezhdenii v guberniyakh osobykh vremennykh komissiy.

23. (1885) Novye uzakonivaniya o piteynoy torgovle//Vestiik finansov, promyshlenposti i torgovli. - 1885. - №33. Pravila o razdrobnoy prodazhe napitkov: Vysoch.utv. 14 may $1885 \mathrm{~g}$.

24. (1881) Obzor Ekaterinoslavskoy gubernii za 1881 g. Prilozhenie k nizhayshemu dolozhu gubernatora Ekaterinoslavskoy gubenii E.I.V. Ekaterinoslav, -1881.

25. (1887) Obzor Ekaterinoslavskoy gubernii za 1887 g. Prilozhenie k nizhayshemu dolozhu gubernatora Ekaterinoslavskoy gubenii E.I.V. Ekaterinoslav, -1887.

26. (1895) Obzor Ekaterinoslavskoy gubernii za 1895 g. Prilozhenie k nizhayshemu dolozhu gubernatora Ekaterinoslavskoy gubenii E.I.V. Ekaterinoslav, -1895.

27. (1899) Obzor Ekaterinoslavskoy gubernii za 1899 g. Prilozhenie k nizhayshemu dolozhu gubernatora Ekaterinoslavskoy gubenii E.I.V. Ekaterinoslav, -1899.

28. (1864) Pamyatnaya kniga Ekaterinoslavskoy gubernii na 1864 g. - Ekaterinoslav, -1864.

29. (1866) Pamyatnaya kniga Ekaterinoslavskoy gubernii na 1867 g. - Ekaterinoslav, -1866.

30. (1900) Pamyatnaya kniga Ekaterinoslavskoy gubernii na $1901 \mathrm{~g}$. - Ekaterinoslav, -1900.

31. (1903) Pamyatnaya kniga na 1903 g. Ekaterinoslav, - 1903 .

32. (2015) Poln. sobr. zakonov Rossiyskoy imperii (PSZ). - Sobr. 3-є. - t.5. - №2946.

33. (1885) Prikaz podatnym inspektoram po guberniyam Evropeyskoy Rosii utv.upravlyayushchim Ministerstvom finansov 12 aug. 1885 // Vestnik finansov, promyshlennosti i torgovli. - 1885. -T. 3 .

34. (1899) RGIA. - F. 1288. - Op.25. - D. 18. Delo ob ustanovlenii v pol'zu dokhodov g. Bakhmuta sbora s tovarov.

35. (1895) RGIA. - F. 573. - Op. 30. - D. 1007.Smeta dokhodov i raskhodov po Bakhmutu za 1895.

36. (1896) RGIA. - F. 573. - Op. 30. - D. 1008. Smeta dokhodov i raskhodov po Bakhmutu za 1896.

37. (1896) RGIA. - F. 573. - Op.30. - D. 1010. Otchet Bakhmutskoy gorodskoy upravy za 1896.

38. (1899) RGIA. - F. 1288. - Op. 6. - D. 84. Smeta dokhodov i raskhodov Bakhmuta za 1899. Otchet Bakhmutskoy gorodskoy upravy za $1899 \mathrm{~g}$.

39. (1916) Spravochnaya kniga Ekaterinoslavskoy gubernii za 1916 g. - Ekaterinoslav.

40. (1912) Smeta Bakhmuta na 1912 g. - Bakhmut. $-121 \mathrm{p}$. 


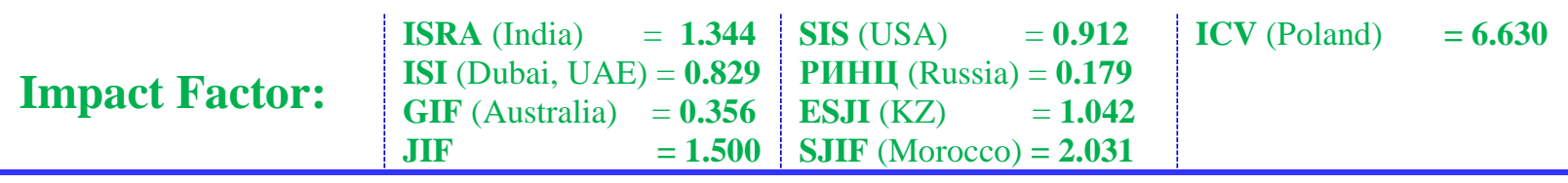

41. Tatarinov SI (1999) Bakhmutskoe zemstvo i narodnoe obrazovanie. Muzey v KhKh1 veke. Artemovsk.

42. Tatarinov SI (2001) Bakhmut. Ocherki istorii, 1783-1917. - Artemovsk, - 2001, - 146 p.

43. Tatarinov SI, Tutova NO (2008) Narisi instorii samovryaduvannya u Bakhmuti ta poviti. Artemovsk, -2008, - 230 p.

44. Tatarinov SI, Tutova NA (2009) K 110 letiyu telefonizatsii Bakhmutskogo uezda//Letopis' Donbassa. - Donetsk, - №6, -2009.

45. Tatarinov SY (2011) 50 rokiv diyal'nosti Bakhmuts'kogo povitogo zemstva. Vistnik LugNU im.T.Shevchenka. Istoricheskie nauki, - №11(222), -2011, - pp.112-122.
46. Tatarinov SY, Fedotov SA (2012) Podatkovi vidnosini u Bakhmuts'komu poviti. Zbirnik prats' KhNPU im.Skovorodi, seriya «Istoriya i geografiya», - vip.45, - Khar'kov, -2012. pp.177-179.

47. Tatarinov SI, Tutova NO, Tutov PM (2013) Bakhmuts'kiy kray-vidatni storinki istoriï. Kharkiv:PP Machulin, 2013, - 408 p.

48. Chicherin BN (1866) O narodnom predstavitel'stve. - Moscow. 1866.

49. (1910) Yuzhno -rossiyskaya vystavka. Ekaterinoslav. -1910.

50. Yarmish ON, Golovko OM (1999) Do pitannya tipiv mistsevogo samovryaduvannya. Vestnik Zaporozhskogo yuridicheskogo instituta. 1999. - №1. 